May 2019

\title{
Enhancing academic self-efficacy and performance among fourth year psychology students: Findings from a short educational intervention
}

Alexis R. Foulstone

Monash University, a.foulstone@uq.edu.au

Adrian Kelly

Queensland University of Technology, a.kelly@qut.edu.au

Follow this and additional works at: https://digitalcommons.georgiasouthern.edu/ij-sotl

\section{Recommended Citation}

Foulstone, Alexis R. and Kelly, Adrian (2019) "Enhancing academic self-efficacy and performance among fourth year psychology students: Findings from a short educational intervention," International Journal for the Scholarship of Teaching and Learning: Vol. 13: No. 2, Article 9.

Available at: https://doi.org/10.20429/ijsotl.2019.130209 


\title{
Enhancing academic self-efficacy and performance among fourth year psychology students: Findings from a short educational intervention
}

\begin{abstract}
Academic self-efficacy is the degree to which students believe they are capable of learning or accomplishing an academic task within a specific area of education. High academic self-efficacy has been associated with positive education outcomes such as enhanced learning, motivation, selfdetermination, and ultimately academic performance. The current study designed, implemented and evaluated an educational intervention to enhance the academic self-efficacy and performance of 21 psychology students enrolled in a group supervised Honours course, the outcome being a thesis dissertation. Students completed pre-intervention surveys in class half way through the course and then another survey after the 8-week intervention. Measures of self-efficacy (based on student responses) were similar over the two assessments. Furthermore, self-efficacy did not predict academic outcomes as determined by two independent examiners' final marks on their thesis. Findings are discussed in relation to limitations of the data and challenges faced when implementing interventions aimed to enhance academic self-efficacy.
\end{abstract}

\section{Keywords}

Academic self-efficacy, academic performance, educational intervention, learning, evaluation.

\section{Creative Commons License}

(c) $($ ) $(\Theta$

This work is licensed under a Creative Commons Attribution-Noncommercial-No Derivative Works 4.0 License.

\section{Cover Page Footnote}

The author thanks Dr Glenys McGowan from The University of Queensland for her mentoring throughout the intervention and proof-reading of the first manuscript. Her advice and support was invaluable. 


\title{
Enhancing Academic Self-Efficacy and Performance among Fourth-year Psychology Students: Findings from a Short Educational Intervention
}

\author{
Alexis R. Foulstone' \& Adrian Kelly ${ }^{2}$ \\ I.The University of Queensland \\ 2. Queensland University of Technology
}

Received 7 February 2017;Accepted 19 September 2018

\begin{abstract}
Academic self-efficacy is the degree to which students believe they are capable of learning or accomplishing an academic task within a specific area of education. High academic self-efficacy has been associated with positive education outcomes such as enhanced learning, motivation, self-determination, and ultimately academic performance. The current study designed, implemented and evaluated an educational intervention to enhance the academic self-efficacy and performance of 21 psychology students enrolled in a group supervised Honours course, the outcome being a thesis dissertation. Students completed pre-intervention surveys in class half way through the course and then another survey after the 8-week intervention. Measures of self-efficacy (based on student responses) were similar over the two assessments. Furthermore, self-efficacy did not predict academic outcomes as determined by two independent examiners' final marks on their thesis. Findings are discussed in relation to limitations of the data and challenges faced when implementing interventions aimed to enhance academic self-efficacy.
\end{abstract}

\section{INTRODUCTION}

Academic self-efficacy refers to a student's belief that they are capable of learning or performing new academic tasks, generally within a specific educational domain (e.g., writing, analysis, synthesis; Meral, Colak, \& Zereyak, 20 I2; Pajares 1996; Schunk, 2003). There is strong evidence that self-efficacy can influence student learning, achievement motivation and academic outcomes (e.g., Honicke \& Broadbent, 2016; Komarraju \& Nadler, 2013; Yusuf, 20II). Despite this, comparatively little empirical research has been published on interventions designed to enhance academic self-efficacy, particularly with undergraduate students enrolled in courses which entail a major research component. To address the gap, this paper describes an action learning project that implemented and evaluated an intervention aimed to improve the self-efficacy of academic skills needed to complete research and a thesis in psychology.

Research-related academic skills include: (I) reading and interpretation; (2) research design, analysis, and reporting; (3) professional skills such as public speaking and networking; and (4) technical skills (Meerah, 20l0). To improve student efficacy of these skills, Meerah concluded that supplementary workshops and specific research training tailored to individual student needs can be beneficial. Students can also be encouraged to use all available resources, consult with peers, and complete additional study to foster greater understanding of relevant material (Payne \& Israel, 2010). However, it remains unclear whether a brief educational intervention incorporating previous practical and theoretical recommendations can increase the self-efficacy of academic research skills, and ultimately academic performance.

Learning activities developed to enhance academic self-efficacy have focused on sources that Bandura (1997) theorized as mastery experience (perceptions of success), vicarious experience (learning from models), verbal persuasion (support) and emotional states (recognizing and managing negative affect). These sources can assist academics in higher education design evidence-based teaching practices to promote self-efficacy (Chang \& Levin, 20I4). For instance, activities that allow students to understand what is needed to succeed can be facilitated by developing criterion-referenced grids and rubrics (e.g., Rosenbaum, 1994). Along with exemplars and opportunities to discuss criteria and standards, such information can enhance student learning and academic development (Rust, Price, \& O’Donovan, 2003). Self-efficacy can also be enhanced through vicarious experience by sharing successful examples of work completed by previous students (e.g., Jenson et al., 20 I I; Schunk, 2003), highlighting stronger and weaker aspects of such work, and discussing how to overcome challenges with persistence and efficacious thinking (Zimmerman \& Kitsantis, 2002). Similarly, detailed and constructive feedback that is delivered in a timely manner can reinforce learning and enhance self-efficacy (Andrade, Wang, Du, \& Akawi, 2009; Panadero, Alonso-Tapia, \& Huertas, 20I2). It is also important to identify when students experience negative emotions about their studies and share strategies to reduce these reactions (Schunk \& Pajares, 2009).

This study aimed to understand whether a short educational intervention could enhance the perceived academic self-efficacy of undergraduate students enrolled in a fourth-year groupsupervised thesis subject. The project also investigated whether academic self-efficacy was positively associated with academic performance, as determined by final examiner's grades for student theses. More specifically, two questions were examined: How can self-efficacy of academic research skills be enhanced for undergraduate students studying a group-supervised thesis in psychology; and how are measures of academic self-efficacy associated with academic performance?

\section{METHOD \\ Participants}

The 'Self-efficacy Intervention'was delivered to 21 fourth-year students completing a research thesis to meet the requirements for an Honours degree in psychology at a major Australian university. Students were primarily female $(90 \%)$, with more than a third (38.1\%) coming from, or having lived the majority of their time outside of Australia. Participants were identified as having lower grades in previous undergraduate studies and were therefore likely to need additional research-related support. Specifically, most had received a credit or lower on general grade point av- 
erage, which is normally insufficient to commence the Honours year.

\section{Measures}

A clear evaluation plan was integral to the action learning project, with post-intervention surveys assessing measures of academic self-efficacy and performance against baseline data (e.g., pre-intervention surveys). Surveys contained questions / items related to academic self-efficacy, perceived academic control, motivation, and Grade Point Averages (GPA). Evidence to determine outcomes of the intervention came from reliable measures used in previous educational research. More specifically, the following inventories were incorporated into the surveys:

\section{Self-efficacy for learning and performance.}

This was measured using a modified version of the Self-efficacy for Learning and Performance (SELP) subscale that is part of the Motivated Strategies for Learning Questionnaire (MSLQ: Pintrich, Smith, Garcia, \& McKeachie, I991).The MSLQ is an 81-item, self-report instrument designed to measure college students' motivational orientations and use of learning strategies as they relate to a specific course (Duncan \& McKeachie, 2005). Altogether, the MSLQ consists of 15 subscales and the instrument has been flexible, allowing sub-scales to be used together or separately, depending on specific needs of the research question. The SELP subscale consists of eight items which were modified for the current context. For example, "I am confident that I can learn the basic concepts taught in this course" was adjusted to "I am confident that I can learn the basic concepts related to completing a thesis in psychology." Scores ranged from I 'strongly disagree' to 5 'strongly agree', and the scale was reliable with a Cronbach alpha of $\alpha=.82$ at both pre- and post-intervention, which is similar to previous research that has also demonstrated the subscale to be a robust measure of self-efficacy with a Cronbach alpha level of .93 (Pintrich, Smith, Garcia, \& McKeachie, 1993).

\section{General self-efficacy.}

This was measured using an adapted version of the New General Self-Efficacy scale (NGSE: Chen, Gully, \& Eden, 200 I; Chen \& Gully, 1997). The NGSE scale is an 8-item measure of general self-efficacy that has been highly reliable when predicting self-efficacy for a variety of tasks in different contexts. Furthermore, it is unidimensional, internally consistent, stable over time, and provides a short but valid measure of general self-efficacy, with Cronbach alpha levels ranging from .85 to .87 , and a test-retest reliability of .66 (Chen et al, 200I). Items were again modified and made specific to the current context (e.g., "When facing difficult tasks related to my thesis, I am certain that I will be able to accomplish them"). In the current study, the adapted NGSE had a Cronbach alpha of .79 for the pre-intervention measure, and $\alpha$ $=.87$ at post-intervention.

\section{Perceived academic control.}

This was measured using an adapted version of the Perceived Academic Control scale (PAC: Perry, Hladkyj, Pekrun, \& Pelletier, 200I; Ruthig, Haynes, Stupnisky, \& Perry, 2009). The PAC scale focuses on students' beliefs about the causes of their academic achievements and failures, and to what degree they believe these outcomes are due to their own behavior, decisions, actions, etc. The scale has eight items measured from I: strongly disagree to 5 : strongly agree, with four items needing to be reverse scored be- cause of negative wording (e.g., "There is little I can do about my performance at university"), resulting in higher scores indicating greater perceived academic control. Items were adapted to the current context and, similar to previous research (e.g., Perry et al, 200 I stated the PAC to have $\alpha=.80$ ), the scale was robust with a Cronbach alpha of .79 at pre-intervention and .78 when assessed after the intervention.

\section{Intrinsic motivation.}

This was measured using the intrinsic motivation subscale of The Situational Motivation Scale (SIMS: Guay,Vallerand, \& Blanchard, 2000). The SIMS is a self-report measure designed to assess the constructs of intrinsic motivation, identified regulation, external regulation, and amotivation (Deci \& Ryan, 1985, 1991). Participants read the question "Why are you currently engaged in this activity?" and then respond to four items (e.g., "because I think that this activity is interesting'), on a 7-point Likert scale ranging from I: corresponds not at all to 7: corresponds exactly. In the current study, the intrinsic motivation subscale was reliable at both pre $(\alpha=.75)$ and post-intervention $(\alpha=.81)$.

\section{Confidence in supervisor.}

This was measured with the statement, "I am confident that my supervisor will be able to help me with any problem I have with my thesis" (0: not at all confident to 7: completely confident). This item was included to assess how much confidence students had in the supervision. Similar to other items, the wording was changed in the post-intervention survey because students had completed their theses: "I am confident that my supervisor has helped me with any problems I have had with my thesis."

\section{Grade point average (GPA).}

Students provided their current GPA (scale from 2: serious fail to 7: high distinction) as a baseline measure of academic performance.

\section{Supervisor ranking.}

The supervisor ranked each student from I: poor to 7: superior in terms of writing and analytical abilities after reading drafts of their work.

\section{Academic performance.}

This was determined by final examiner marks on individual student theses.

\section{Usefulness of intervention.}

The usefulness of various components of the intervention was assessed in the post-intervention survey. More specifically, questions sought feedback on how students perceived the intervention (e.g., sharing of information through the Facebook Group page, supervisor's feedback on drafts, exemplars of previous work, thesis section checklists). Students indicated how useful they perceived these features of the intervention, ranging from I: not at all useful to 7: extremely useful.

The pre-intervention survey took approximately 18 minutes to complete in class, with the post-intervention survey taking approximately 20 minutes to complete in scheduled times after classes were finished (e.g., due to additional questions about the usefulness of the intervention). Clearance from the Ethics Committee of The University of Queensland was granted prior to the intervention being implemented. 


\section{Procedure}

The Self-efficacy Intervention was designed and evaluated over two semesters across one year. At UQ, undergraduate students' complete thesis units in two semester blocks of I 3 weeks. In Week 7 of Semester I, students identified as being low in performance (see Participants) were invited to participate in an educational innovation program designed to improve their academic skills. The program consisted of 13 lectures, 13 tutorials, and a consultation hour in the first semester. These lectures focused on building writing skills, conceptualization skills, and skills in the integration of academic literature into research questions. Students sequentially completed sections of their honours thesis (e.g., introduction, method, etc), and these were submitted for feedback and grading. Students worked together in the same groups (e.g., constructing surveys, research ethics applications, data collection and entry), receiving face-to-face group supervision and advice within tutorials. As part of the course, peer assisted study was facilitated by the teacher to maximise learning, and to build connections and support across the cohort (Huijser, Kimmins, \& Evans, 2008). To assist with planning the intervention, students indicated how competent they were with specific academic skills (writing, statistical analysis, time management), and the intervention was weighted towards areas where problems predominated.

To satisfy requirements of the course, students submitted drafts of their Introduction and Method chapters in Week 13 of Semester I. During the following four weeks (e.g., during the mid-year break), the supervisor read these drafts providing students with extensive feedback (track changes, suggested comments, etc.). To assist students to gain a more objective understanding of what was expected in their drafts, a criteria-referenced/standards rubric (e.g., Panadero \& Romero, 20I4; Reddy \& Andrade, 2010) was developed (Appendix A). In addition to guiding student writing and providing feedback, these sheets gave the supervisor a stronger understanding of the students' writing and analytical abilities.

In the second semester, targeted sessions (3x) were delivered addressing statistical design, analysis and results presentation (across an 8-week span). Consultation hours across the semester continued. To address the possible ethical concern of students feeling coerced into completing the evaluative component of the intervention (e.g., Bournot-Trites \& Belanger, 2005), it was made clear that they were not obliged to participate in the pre- and post-intervention surveys and would not be disadvantaged in terms of supervisory support. All students agreed to participate, and after completing pre-intervention surveys, information was disclosed about a Private Facebook Group page that had been created for peer and supervisory discussion regarding research and learning areas that students were experiencing difficulty.

The Facebook Group was a core aspect of how information was communicated and disseminated to students. On the Facebook Group page, credible messages from students were encouraged and reinforced through verbal (Chang \& Levin, 20I4) and online encouragement and efficacy enhancement. In particular, student responses to activities and tasks were monitored (Jungert \& Rosander, 2010), with the intention of positively influencing self-efficacy of a particular topic (e.g., students who demonstrated mastery were praised and encouraged to attempt more difficult tasks). Supervisor feedback on drafts and student e-mails were also responded to promptly, with positive aspects of student work and questions being acknowledged (promoting experiences of mastery).

Enhancing academic self-efficacy through vicarious experience learning was achieved by having students share information and provide advice about a particular task that other students indicated having difficulties with, such as analyzing or interpreting statistical data (e.g., Day et al., 2007; Margolis \& McCabe, 2006; Schunk, 2003). Video links showing how specific research tasks could be completed using relevant data-analysis packages, as well as written exemplars of sections relevant to student theses (e.g., Introduction, Method, Results, etc.) were made accessible through the Facebook Group page. Specific and purposeful comments regarding these sections were provided to assist learning and guide student writing. Furthermore, checklists were constructed for students to gain a clearer understanding of what to (and not to) include in specific sections of their theses. These components of the intervention aimed to assist students' master academic tasks, again linking to experiences that might positively influence the self-efficacy of research-related skills and performance.

To address the potential high levels of stress and anxiety that Honours students face when completing a substantial piece of research, one-to-one consultations were offered to discuss problems that students were experiencing. Furthermore, three supplementary class times were made available to assist with completion of statistical analyses. Support was provided by following up with students to ask whether they had understood the advice that had been provided, scaffolding understanding, and supportive acknowledgement of stress/anxiety. Extensions on drafts were also granted when clashes with other course assessments were identified.

Throughout the intervention, polls were developed within the Facebook Group for student feedback to determine how the intervention was progressing and what specific research-related assistance was required. This feedback assisted in determining whether the intervention needed to be modified. Such monitoring/reflection is an integral part of the evaluation cycle of the overall Action Learning Project (Larrivee, 2000).

\section{Data analyses}

To examine whether measures of self-efficacy improved after the intervention, paired-sampled t-tests were conducted. Correlation analyses were used to assess whether measures of self-efficacy, perceived control, intrinsic motivation, baseline GPA, and supervisor rankings of students' writing and analytical abilities were positively associated with academic performance. Dichotomous measures of self-efficacy were also created using a median split (e.g., lower vs higher self-efficacy) and an independent t-test assessed whether students with higher as opposed to lower self-efficacy had significantly better thesis marks. The attrition rate was low - only one student did not complete the follow-up assessment. 
Figure I. Pre-and post-intervention scores for academic self-efficacy, perceived academic control, and intrinsic motivation.

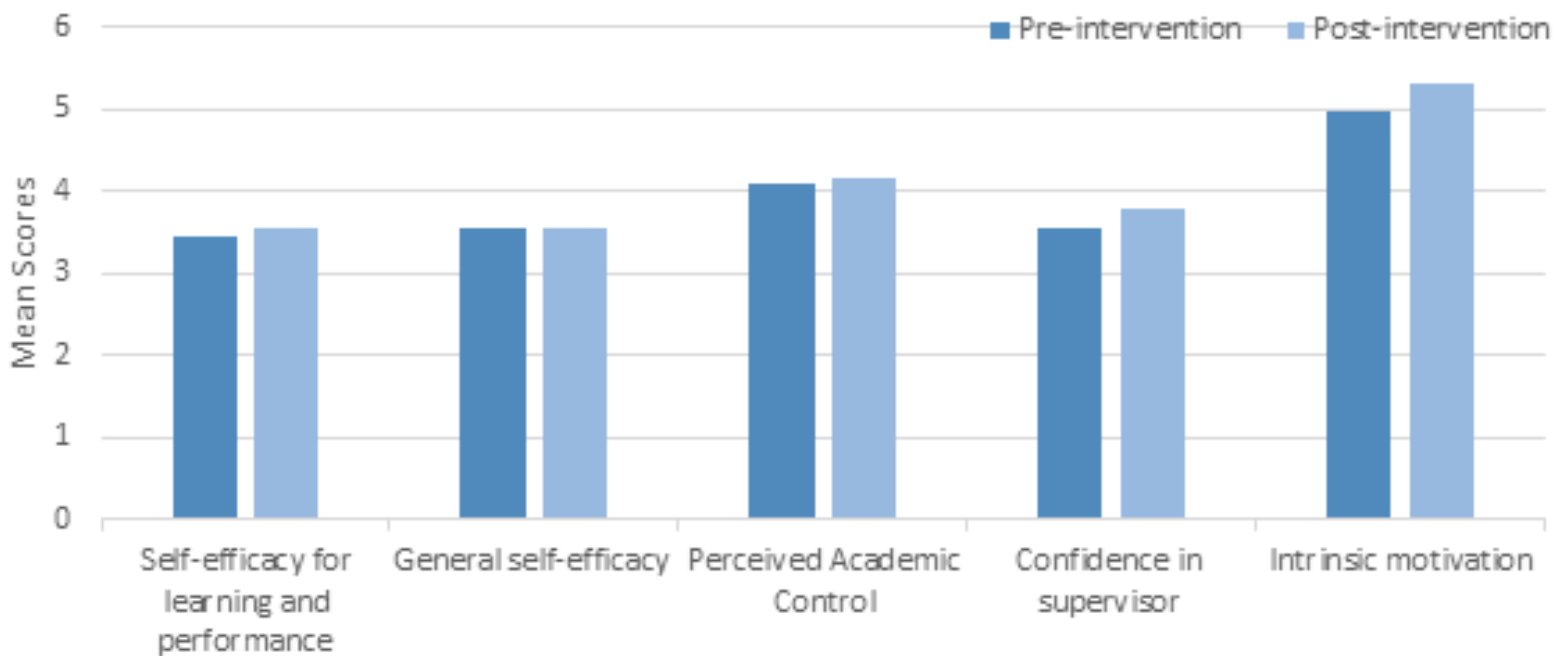

\section{RESULTS}

\section{Changes in self-efficacy, motivation and perceived control.}

Average scores of self-efficacy for learning and performance, general self-efficacy, perceived academic control, students' confidence in the supervisor, and intrinsic motivation pre- and post-intervention are presented in Figure I. Prior to the intervention, students reported moderate self-efficacy for learning and performance $(M=3.53, S D=0.49)$, general self-efficacy for psychology $(M=3.56, S D=0.4 I)$, and perceived academic control $(M=$ $4.16, S D=0.49)$. Although perceived self-efficacy and academic control (using a 5 -point scale) were slightly greater after the intervention, paired-sample t-tests revealed that differences with pre-intervention scores were not significant. However, students had significantly greater intrinsic motivation (on a 7-point scale) after the intervention $(M=5.30, S D=1.01)$, compared to before the intervention $(M=4.97, S D=1.02), t(18)=1.97, p=.06$, when an alpha level of 0.1 was set.

In terms of perceived confidence in the supervisor assisting with thesis-related problems, prior to the intervention, students who had come to Australia from overseas had significantly lower confidence $(M=3.13, S D=0.84)$ compared to (local) students who were raised in Australia for the majority of their lives $(M=$ $3.75, S D=0.45), t(18)=2.18, p<.05$. However, perceived confidence in the supervisor increased for both types of students and there were no longer significant differences between international $(M=3.63, S D=0.74)$ and Australian students after the intervention $(M=4.00, S D=0.60), t(I 8)=1.24, p=.23$.

\section{Academic performance outcomes.}

All theses for the 21 students were passed by external examiners with marks ranging from 60 to 82 out of $100(M=72.05$, $S D=5.25$ ). Although on average students who were categorized as having greater self-efficacy for learning and performance prior to the intervention received higher marks $(M=74.00, S D=$ 4.42) compared to students with lower self-efficacy for learning and performance $(M=70.09, S D=4.42)$, this difference was not statistically significant, $t(I 8)=1.72, p=.12$. Similarly, after the intervention, students categorized as having higher general self-efficacy for research in psychology received higher marks on their final thesis $(M=73.50, S D=5.42)$ compared to students with lower self-efficacy $(M=70.25, S D=4.89)$, but this difference was not significant, $t(18)=1.36, p=.19$.

Correlation analyses showed that both self-efficacy for learning and performance, as well as general self-efficacy for psychology prior to the intervention were positively associated with academic outcomes as determined by final examiners' marks (Table I). Post-intervention measures of self-efficacy were also positively associated with academic performance but were not statistically significant. The only independent variables that were significantly associated with academic outcomes were supervisors' rankings of student academic capabilities prior to the intervention $(r=.48, p<.05)$, and students' perceived academic control after the intervention $(r=.40, p<.10)$. Student reports of their GPA prior to the intervention (e.g., baseline academic performance) and intrinsic motivation pre- and post-intervention were both negatively, but non-significantly, associated with final thesis marks.

Supervisor rankings of students' academic abilities were positively and significantly associated with self-efficacy for learning and performance at both pre- $(r=.49, p<.05)$ and post-intervention $(r=.34, p<.05)$. Similarly, supervisor rankings prior to the intervention were positively and significantly correlated with perceived academic control after the intervention $(r=.39$, $p<.05$ ). The two measures of self-efficacy were also strongly and positively correlated at both pre and post-intervention assessments $(p<.00 I)$.

\section{Student evaluation of the intervention.}

Students indicated on a 7-point Likert scale that the Facebook group page as a means of communication $(M=6.65, S D=$ 0.59 ) was the most useful aspect of the intervention (Figure 2). In contrast, Blackboard as a means of communication $(M=3.35$, SD $=1.73)$ and emotional support from the supervisor $(M=4.45$, $S D=1.50$ ) were perceived as the least useful. All other aspects of the intervention were perceived to be useful with average rankings ranging from five and six. 


\begin{tabular}{|c|c|c|c|c|c|c|c|c|c|c|c|}
\hline Measure & $M(S D)$ & 1 & 2 & 3 & 4 & 5 & 6 & 7 & 8 & 9 & 10 \\
\hline I.Academic performance (T2) & $72.05(5.25)$ & & & & & & & & & & \\
\hline 2. GPA (TI) & $5.76(0.48)$ & -.21 & & & & & & & & & \\
\hline 3. Supervisor ranking $(\mathrm{TI})$ & $4.43(1.02)$ & $.48 *$ & .25 & & & & & & & & \\
\hline 4. Self-efficacy L\&P\# (TI) & $3.53(0.48)$ & .20 & -.08 & $.49 *$ & & & & & & & \\
\hline 5. General self-efficacy $(\mathrm{TI})$ & $3.58(0.4 \mathrm{I})$ & .10 & -.12 & $.31^{\wedge}$ & $.86 * *$ & & & & & & \\
\hline 6. Perceived academic control (TI) & $4.16(0.47)$ & .10 & .06 & $.32^{\wedge}$ & .25 & .18 & & & & & \\
\hline 7. Intrinsic motivation $(\mathrm{TI})$ & $4.91(1.03)$ & -.25 & .01 & .19 & .25 & .11 & $.49 *$ & & & & \\
\hline 8. Self-efficacy L\&P (T2) & $3.48(0.49)$ & .23 & -.25 & .30 & $.69 * *$ & $.77^{* *}$ & .09 & .01 & & & \\
\hline 9. General self-efficacy (T2) & $3.56(0.54)$ & .20 & -.12 & $.34 *$ & $.68 * *$ & $.82 * *$ & .18 & .14 & $.92 * *$ & & \\
\hline 10. Perceived academic control (T2) & $4.06(0.47)$ & $.40^{\wedge}$ & -.08 & $.39 *$ & .14 & .08 & $.66 * *$ & .23 & .29 & .28 & \\
\hline II. Intrinsic motivation (T2) & $5.33(0.99)$ & -.11 & -.13 & .15 & $.32^{\wedge}$ & .13 & .31 & $.74 * *$ & .10 & .08 & .21 \\
\hline
\end{tabular}

\section{DISCUSSION}

The overarching aim of this action learning project was to implement and evaluate an educational intervention designed to enhance the academic self-efficacy and performance of 21 Honours students completing a group-supervised thesis in psychology. After applying a 'Self-efficacy Intervention' over an 8-week period during the second half of the year, students perceived the intervention to be very useful in assisting them complete their theses. While the intervention was perceived to be helpful, the intervention did not appear to alter perceptions of self-efficacy. This points to the possibility that self-efficacy at around the honours level is relatively stable and difficult to shift, and that earlier policies and strategies to improve self-efficacy might be useful (Lane \& Lane, 200I; Pajares, 2003, Pajares \& Miller, 1994; Schunk, 2003). Together, these findings suggest that interventions aiming to enhance academic self-efficacy may be more beneficial when implemented during earlier stages of their university experiences such as in first year (e.g., freshman years). Similarly, it is important to evaluate academic self-efficacy over longer periods as students' progress through to later years of tertiary study (Artino et al., 20I2). Perhaps key milestones (such as the award of a degree) are markers that have more of an impact on self-efficacy. It is also possible that the intervention had insufficient power to change self-efficacy - perhaps if it was more intensive or contained more contact time, self-efficacy would have changed. While the number of weeks of the program was commensurate with skills-focused programs where improvements in self-efficacy would be expected, it is possible that a more intensive program would have resulted in shifts in efficacy.

Although self-efficacy for learning and performance (e.g., Pintrich et al, 1993) and general self-efficacy (Chen et al, 200I) were positively associated with later academic performance (as determined by final thesis marks), the associations were not statistically significant. Such findings are contrary to previous research which has consistently demonstrated academic self-efficacy to be moderately associated with performance (e.g., Hon-

Figure 2. Usefulness of components of the 'Self-efficacy Intervention'

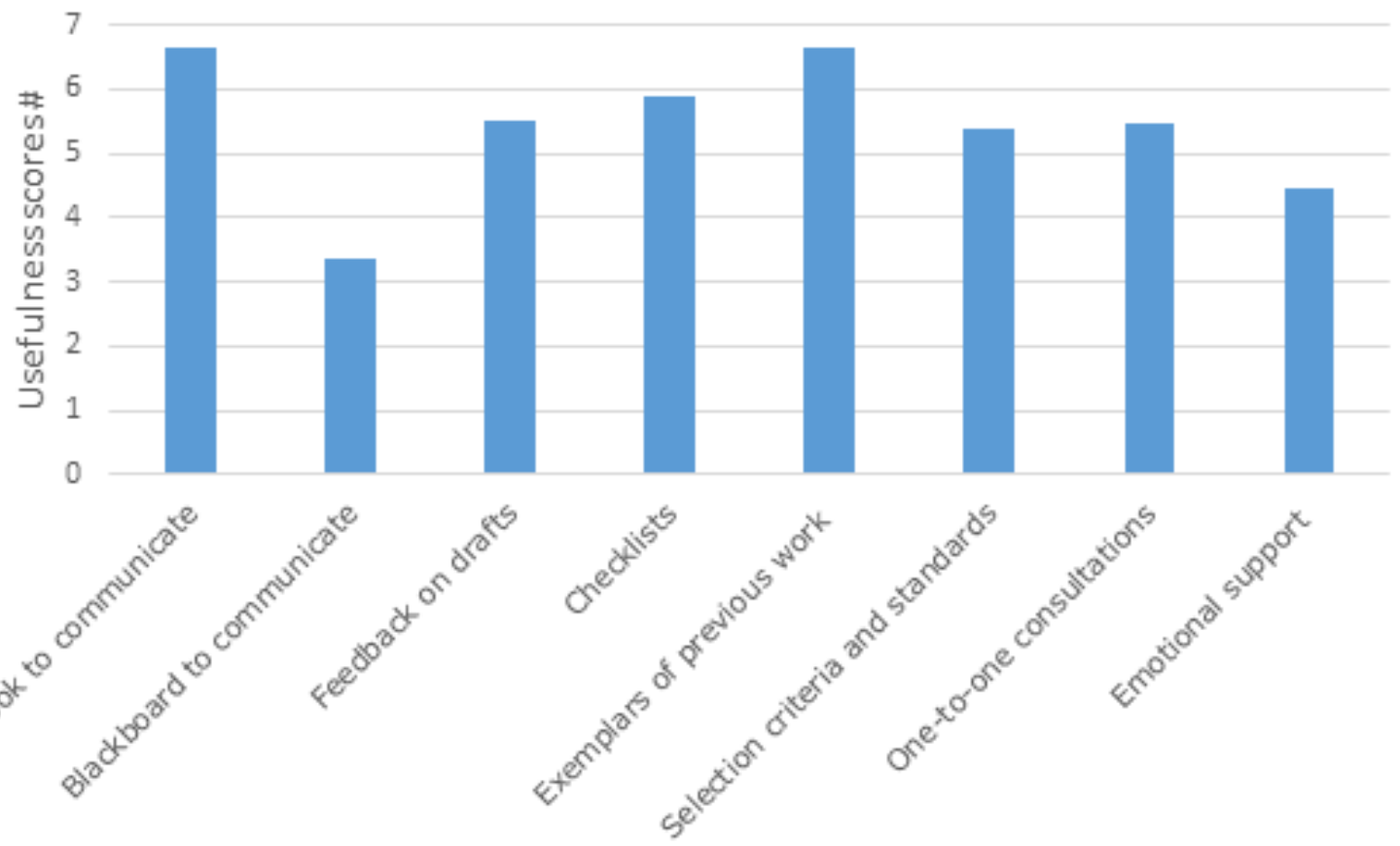


icke \& Broadbent, 20I6; Komarraju \& Nadler, 20I3; Yusuf, 20I I). These studies incorporated a variety of representative measures with a diverse range of student samples, and according to Robbins et al's (2004) meta-analysis of psychosocial and study skill factors, academic self-efficacy and achievement motivation have been the best predictors of academic performance (as determined by students' GPA). However, to the author's knowledge, the current Action Learning Project was the first to examine how academic self-efficacy is associated with performance using a sample of undergraduate students (the majority of whom were female) completing a substantial piece of scientific research (e.g., thesis) in psychology. Given the cohort's lack of ambition to establish research-related careers in psychology, many students may have underestimated their own academic abilities, and other contextual influences (e.g., availability of supporting resources) or academic-related skills (e.g., time management, problem-solving and coping strategies) could have played important roles explaining academic performance.

\section{CHALLENGES FOR THE INTERVENTION AND EVALUATION}

There were other constraints on the intervention and how it was evaluated that would explain the non-significant and conflicting findings. First, the intervention was applied to a small sample of students, resulting in analyses lacking power to detect statistical significance, and preventing complex analyses from being conducted on the data (e.g., moderated or mediated analyses).Accordingly, only descriptive statistics of the outcomes from the innovation were reported. Second, measures of self-efficacy may have been weak in relation to predicting academic success when writing a thesis, and third, it was possible that activities in the intervention (although perceived as useful by the students) did not facilitate improvements in academic self-efficacy. Students were also mainly female and the effects of the intervention may have differed for males who traditionally have higher perceptions of academic self-efficacy in science-related fields of study (e.g., Lindstrom \& Sharma, 20II; Pajares, 2002). In general, females have also been more likely to devalue their performance and be self-critical compared to males (Arch, 1987). Future research is required using larger samples that include males, and specific measures to assess the self-efficacy of academic research skills. Other teaching strategies to enhance self-efficacy also need to be designed, applied and evaluated.

Without all originally planned resources being implemented, important aspects of self-efficacy would not have been addressed adequately (e.g., mastery and vicarious experiences). The action learning plan had intended to incorporate student modelling of particular research-related tasks, such as analyzing or interpreting statistical data. Initially, it was intended that models would explain what they were doing and thinking during each step of the task or activity (Margolis \& McCabe, 2006; Schunk, 2003). Video links showing previous Honours students undertaking specific research tasks were planned to be made available to students online and in class. However, without sufficient time and resources, the intervention could not promote vicarious learning through this kind of modelling. It is recommended that future teaching innovations include models, particularly those who share similar characteristics to students which the intervention is targeted (e.g., Schunk \& Pajares, 2009).
Personal observation and interactions with students unveiled that they were very anxious and stressed in relation to how the group-supervised thesis was administered. Students indicated having problems related to deadlines for drafts of work competing with other program requirements, perceived inequity of how individually supervised students completed their thesis, lack of statistical and research competence from previous undergraduate experiences, and that class attendance took time away from writing the thesis. Students also reported that emotional support from the supervisor was not as useful as other aspects of the intervention. Future research will utilize information obtained from focus groups to decipher how emotional support can be facilitated more efficiently by supervisors of a group-supervised thesis, when there are many competing program requirements and students have a strong aversion to statistics and research in general.

Some other challenges faced in the current Action Learning Project included the limited time available to produce research tasks of varying levels of difficulty for students to master. It was also difficult to promote mastery experiences to students when drafts of work were very poor (e.g., it would be unethical to give students false confidence by praising substandard work). In combination, all of the above factors may have contributed to the intervention having lower than expected effects on students' perceived academic self-efficacy.

\section{Factors that influenced academic self-efficacy and performance}

The data suggests that the strongest predictor of academic performance (e.g., final thesis marks), was the supervisor's initial rankings of the student's writing and analytical capabilities. These rankings were also significantly associated with student perceptions of self-efficacy for learning and performance, as well as perceived academic competence. Supervisor perceptions of students' academic abilities were closely associated with the level of criticism students received on drafts of their Introductions submitted prior to the intervention. Given that the Introduction was a central and substantial component of the final thesis, students who submitted poor-quality drafts and received feedback that was critical of it, may have experienced lower self-efficacy and perceived competence from the outset of the intervention. Such a finding supports the argument that past performances (or external perceptions of performance) may be a stronger influence on self-efficacy than the influence of self-efficacy on future performance (Chang \& Levin, 20l4).

The use of a Private Facebook Group page as a means of communication to enhance learning and teaching was perceived by students to be the most useful feature of the intervention. In addition to being an important way to communicate and share information relevant to enhancing the academic research skills of students, this Group page was a valuable research tool for the collection of data. The Group page remained active after classes had finished and students were reminded about completing the post-intervention survey. Attrition from the study was low. However, given that limited research has evaluated Facebook as a teaching intervention for academic self-efficacy and tool for collecting student data, it is too early to recommend that the platform be incorporated in other higher education contexts. In a time where information technologies continue to revolutionize teaching and learning in tertiary education (e.g., Artino, 20I2), it 
is recommended that future research continues to examine the usefulness of Facebook as an educational and evaluative resource with other cohorts of students and disciplines.

It is assumed that aspects of the prescribed curriculum also influenced students' self-efficacy and academic performance. As part of the group-supervised thesis, students were expected to attend weekly lectures where they received additional guidance from a senior lecturer. Students were also offered a half-hour consultation with a statistician to discuss analytical problems related to their research. Students were encouraged to provide peer support, and the supervisor observed benefits that these students received in terms of emotional support (particularly through the Facebook Group page).

\section{CONCLUSION}

The intervention was not associated with improvements in that self-efficacy did not improve significantly after the intervention, but there was a trend indicating that pre-intervention self-efficacy was positively associated with academic performance, and the intervention was perceived as useful to participants. It is possible that larger numbers, or a more intensive program would have led to changes in academic self-efficacy, or that changes would have been more evident with a control group (particularly if low-performing students commonly report decreases in academic self-efficacy across academically strenuous years like the honours year). Students did find particular features of the intervention (e.g., communicating and providing information via the Facebook Group page) highly beneficial, pointing to the potential value of improving academic and social connectivity and support during academic years where pressures are notably high.

\section{Acknowledgements}

The author thanks Dr Glenys McGowan from The University of Queensland for her mentoring throughout the intervention and proof-reading of the first manuscript. Her advice and support was invaluable.

\section{REFERENCES}

Andrade, H. L., Wang, X., Du,Y., \& Akawi, R. L. (2009). Rubric-referenced self-assessment and self-efficacy for writing. The Journal of Educational Research, 102, 287-302.

Arch, E. C. (1987). Differential responses of females and males to evaluative stress: Anxiety, self-esteem, efficacy, and willingness to participate. In R. Schwarzer, H. M. van der Ploeg \& C. D. Spielberger (Eds.), Advances in test anxiety research (Vol. 5 , pp. 97-106). Hillsdale, NJ: Erlbaum.

Artino,A. R. (20I2). Academic self-efficacy: from educational theory to instructional practice. Perspectives on Medical Education, I, 76-85.

Artino, A. R., Dong, T., DeZee, K. J., Gilliland, W. R., Waechter, D. M., Cruess, D. F., \& Durning, S. J. (20I2). Development and initial validation of a survey to assess students' self-efficacy in medical school. Military Medicine, I77, 3 I-37.

Bandura, A. (1997). Self-efficacy:The Exercise of Control. New York, NY:W. H. Freeman and Company.

Bournot-Trites, M., \& Belanger, J. (2005). Ethical dilemmas facing action researchers. The Journal of Educational Thought, 39 , 197-2। 5 .

Chang,A., \& Levin, R. F. (20I4). Tactics for teaching evidence-based practice: Improving self-efficacy in finding and appraising evi- dence in a master's evidence-based practice unit. Worldviews on Evidence-Based Nursing, I I, 266-269.

Chen, G., \& Gully, S. (1997). Specific self-efficacy, general self-efficacy, and self-esteem: Are they distinguishable constructs? Paper presented at the $57^{\text {th }}$ Annual Meeting of the Academy of Management, Chicago.

Chen, G., Gully, S. M., \& Eden, D. (200I).Validation of a New General Self-Efficacy Scale. Oganizational Research Methods, 4, 62-83.

Day, E. A., Boatman, P. R., Kowollik, V., Espejo, J., McEntire, L. E., \& Sherwin, R. E. (2007). Collaborative training with a more experience partner: Remediating low pre-training self-efficacy in complex skill acquisition. Human Factors, 49, I I 32- I I 48.

Deci, E. L., \& Ryan, R. M. (1985). Intrinsic Motivation and Self-Determination in Human Behavior. New York: Plenum.

Deci, E. L., \& Ryan, R. M. (I99I). A motivational approach to self: Integration in personality. In R. Dienstbier (Ed.), Nebraska Symposium on motivation: vol. 38. Perspectives on motivation. (pp. 237-288). Lincoln: University of Nebraska press.

Duncan, T. G., \& McKeachie, W. J. (2005). The Making of the Motivated Strategies for Learning Questionnaire. Educational Psychologist, 40, I I7-128.

Guay, F., Vallerand, R. J., \& Blanchard, C. (2000). On the assessment of situational intrinsic and extrinsic motivation: The Situational Motivation Scale (SIMS). Motivation and Emotion, 24, $175-213$.

Huijser, H., Kimmins, L., \& Evans, P. (2008). Peer assisted learning in flexi mode: Developing an online learning community.Journal of Peer Learning, I, 5I-60.

Honicke, T., \& Broadbent, J. (2016). The influence of academic self-efficacy on academic performance: A systematic review. Educational Research Review, I 7, 63-84.

Jenson, R.J., Petri,A. N., Day,A. D., Truman, K. Z., \& Duffy, K. (20I I). Perception of self-efficacy among STEM students with disabilities. Journal of Postsecondary Education and Disability, 24, 269-283.

Jungert, T., \& Rosander, M. (20I0). Self-efficacy and strategies to influence the study environment. Teaching in Higher Education, 15, 647-659.

Komarraju, M., \& Nadler, D. (2013). Self-efficacy and academic achievement: Why do implicit beliefs, goals, and effort regulation matter? Learning \& Individual Difference, 25, 67-72.

Lane, J., \& Lane, A. (200I). Self-efficacy and academic performance. Social Behavior and Personality:An International Journal, 29, 687-693.

Larrivee, B. (2000). Transforming teaching practice: Becoming the critically reflective teacher. Reflective Practice: International and Multidisciplinary Perspectives, I, 293-307.

Lindstrom, C., \& Sharma, M. D. (20I I). Self-efficacy of first year university physics students: Do gender and prior formal instruction in physics matter? International Journal of Innovation in Science and Mathematics Education, 19, I- 19.

Margolis, H., \& McCabe, P. P. (2006). Improving self-efficacy and motivation:What to do, what to say. Intervention in School and Clinic, 4 I , 2 I 8-227.

Meerah, T. S. M. (20I0). Readiness of preparing postgraduate students in pursuit of their doctoral programme. Procedia Social and Behavioral Sciences, 9, 184-188.

Meral, M., Colak, E., \& Zereyak, E. (20I2). The relationship between self-efficacy and academic performance. Procedia So- 
cial and Behavioral Sciences, 46, I| |43- I | 46.

Ning, H. K., \& Downing, K. (2010). The impact of supplemental instruction on learning competence and academic performance. Studies in Higher Education, 35, 921-939.

Panadero, E. Alonso-Tapia, J., \& Huertas, J.A. (20I2). Rubrics and self-assessment scripts effects on self-regulation, learning and self-efficacy in secondary education. Learning and Individual Differences, 22, 806-8I3.

Panadero, E., \& Romero, M. (20I4). To rubric or not to rubric? The effects of self-assessment on self-regulation, performance, and self-efficacy. Assessment in Education: Principles, Policy \& Practice, 21 , I33- 148.

Pajares, F. (1996). Self-efficacy beliefs in academic settings. Review of Educational Research, 66, 543-578.

Pajares, F. (2002). Gender and perceived self-efficacy in self-regulated learning. Theory into practice, 4I, II6-I25.

Pajares, F. (2003). Self-efficacy beliefs, motivation, and achievement in writing:A review of the literature. Reading \& Writing Quarterly, 19, 139-158.

Pajares, F., \& Miller, M. D. (1994). Role of self-efficacy and self-concept beliefs in mathematical problem solving:A path analysis. Journal of Educational Psychology, 86, 193-203.

Payne, J. \& Israel, N. (2010). Beyond teaching practice: Exploring individual determinants of student performance on a research skills module. Learning and Individual Differences, 20, 260-264.

Perry, R. P., Hladkyj, S., Pekrun, R. H., \& Pelletier, S. T. (200 I). Academic control and action control in the achievement of college students:A longitudinal field study. Journal of Educational Psychology, 93, 776-789.

Pintrich, P. R., Smith, D. A. F., Garcia,T., \& McKeachie, W. J. (199I). A Manual for the Use of the Motivated Strategies for Learning Questionnaire (MSLQ). Ann Arbour: University of Michigan, National Centre for Research to Improve Postsecondary Teaching and Learning.

Pintrich, P. R., Smith, D. A. F., Garcia, T., \& McKeachie, W. J. (1993). Reliability and predictive validity of the Motivated Strategies for Learning Questionnaire (MSLQ). Educational \& Psychological Measurement, 53, 80 I-8I3.
Reddy,Y. M., \& Andrade, H. (20I0). A review of rubric use in higher education. Assessment \& Evaluation in Higher Education, 35, 435-448.

Robbins, S. B., Lauver, K., Le, H., Davis, D., Langley, R., \& Carlstrom, A. (2004). Do psychosocial and study skill factors predict college outcomes? A meta-analysis. Psychological Bulletin, I30, $26 \mid-288$.

Rosenbaum, J. (1994). Assessment: An overview. In W. G. Christ (Ed.), Assessing communication education: $A$ handbook for media, speech, and theater educators (pp. 3-30). Hillsdale, NJ: ErIbaum.

Rust, C., Price, M., \& O’Donovan, B. (2003). Improving students' learning by developing their understanding of assessment criteria and processes. Assessment \& Evaluation in Higher Education, 28, I47-164.

Ruthig, J. C., Haynes, T. L., Stupnisky, R. H., \& Perry, R. P. (2009). Perceived academic control: Mediating the effects of optimism and social support on college students' psychological health. Social Psychology of Education, 12, 233-249.

Schunk, D. H. (2003). Self-efficacy for reading and writing: Influence of modeling, goal setting, and self-evaluation. Reading \& Writing Quarterly, 19, I59-I72.

Schunk, D. H., \& Pajares, F. (2009). Self-efficacy theory. In K. R. Wentzel \& A. Wigfield (EDs.), Handbook of Motivation at School (pp. 35-53). New York: Routledge.

Yusuf, M. (20I I). The impact of self-efficacy, achievement motivation, and self-regulated learning strategies on students' academic achievement. Procedia Social and Behavioral Sciences, 15, 2623-2626.

Zaccagnini, M., \& Verenikina, I. (20/3//4). Peer assisted study sessions for postgraduate international students in Australia. Journal of Peer Learning, 6, 86- 102.

Zimmerman, B. J., \& Kitsantas, A. (2002). Acquiring writing revision and self-regulatory skill through observation and emulation. Journal of Educational Psychology, 94, 660-668. 


\begin{tabular}{|c|c|c|c|}
\hline \multicolumn{4}{|c|}{ APPENDIX A. Criteria and standards for drafts of Introductions } \\
\hline \multirow{2}{*}{ Criteria } & \multicolumn{3}{|c|}{ Standards } \\
\hline & Improvement needed & Good standard & High standard \\
\hline $\begin{array}{l}\text { Interesting opening } \\
\text { that clearly identi- } \\
\text { fies the importance } \\
\text { of the topic }\end{array}$ & $\begin{array}{l}\text { The topic and importance } \\
\text { need to be explained more } \\
\text { clearly. Opening section needs } \\
\text { to explain how intro will be } \\
\text { structured. }\end{array}$ & $\begin{array}{l}\text { The topic and importance have } \\
\text { been adequately identified. } \\
\text { Opening section gives reader a } \\
\text { clear understanding of what to } \\
\text { expect. }\end{array}$ & $\begin{array}{l}\text { Insightful and interesting topic } \\
\text { that has been clearly identified } \\
\text { and its importance is clear. }\end{array}$ \\
\hline $\begin{array}{l}\text { Relevant literature } \\
\text { has been rec- } \\
\text { ognised, well organ- } \\
\text { ised and critically } \\
\text { reviewed }\end{array}$ & $\begin{array}{l}\text { Limited literature presented, or } \\
\text { relevance of the literature is un- } \\
\text { clear. Little or no critical analysis. } \\
\text { Literature review needs better } \\
\text { organisation. }\end{array}$ & $\begin{array}{l}\text { Well organised literature review } \\
\text { and relevance to the topic and } \\
\text { aims were clear. Adequate crit- } \\
\text { ical analysis / reflection of the } \\
\text { literature. }\end{array}$ & $\begin{array}{l}\text { Very clear, sound reasons } \\
\text { provided for the literature that } \\
\text { has been reviewed. Perceptive } \\
\text { critical analysis / reflection of } \\
\text { the learning. Literature review } \\
\text { was very well organised. }\end{array}$ \\
\hline $\begin{array}{l}\text { Theoretical } \\
\text { framework }\end{array}$ & $\begin{array}{l}\text { No theoretical framework, } \\
\text { limited establishment of an argu- } \\
\text { ment. Unclear why key variables } \\
\text { may be associated. }\end{array}$ & $\begin{array}{l}\text { Theoretical framework and } \\
\text { arguments are clear. Clear un- } \\
\text { derstanding of why and how key } \\
\text { variables may be associated. }\end{array}$ & $\begin{array}{l}\text { Comprehensive and critical un- } \\
\text { derstanding of previous theories } \\
\text { related to the topic. }\end{array}$ \\
\hline $\begin{array}{l}\text { Gaps in the liter- } \\
\text { ature identified. } \\
\text { Aims and hypoth- } \\
\text { eses related to } \\
\text { the question and } \\
\text { literature }\end{array}$ & $\begin{array}{l}\text { No or limited identification of } \\
\text { potential gaps in the literature. } \\
\text { Limited discussion of how } \\
\text { current research will address } \\
\text { these gaps. Aims incompletely } \\
\text { described and/or inappropri- } \\
\text { ate hypothesis and evaluation. } \\
\text { Unclear how hypotheses link to } \\
\text { the review. }\end{array}$ & $\begin{array}{l}\text { Adequate identification of gaps } \\
\text { in the literature and how the } \\
\text { research plans to address them. } \\
\text { Appropriate hypotheses and } \\
\text { evaluation that addresses the } \\
\text { question / aims. Aims are clear } \\
\text { given what literature has been } \\
\text { presented. }\end{array}$ & $\begin{array}{l}\text { Thoughtful identification of } \\
\text { relevant gaps in the literature } \\
\text { and how the research plans to } \\
\text { address these gaps. Creative, } \\
\text { well-articulated hypotheses, with } \\
\text { evaluation that addresses the } \\
\text { question / aims. }\end{array}$ \\
\hline Quality of writing & $\begin{array}{l}\text { Writing difficult to understand } \\
\text { and expression needs attention. }\end{array}$ & $\begin{array}{l}\text { Satisfactory presentation and } \\
\text { quality of written expression. }\end{array}$ & $\begin{array}{l}\text { Clear, logical presentation with } \\
\text { fluent written expression. } \\
\end{array}$ \\
\hline \multicolumn{4}{|l|}{ NAME: } \\
\hline \multicolumn{4}{|l|}{ Comments: } \\
\hline
\end{tabular}

